\title{
DESENVOLVIMENTO DO SISTEMA DE INOVAÇÃO: O ESTABELECIMENTO DA INDÚSTRIAAERONÁUTICA NA REGIÃO ADMINISTRATIVA CENTRAL (SP)
}

Fernando Bueno de Oliveira* Sônia Regina Paulino**

\section{Resumo:}

O artigo enfoca o estabelecimento, nos últimos sete anos, da indústria aeronáutica na Região Administrativa Central (SP), o que introduziu um elemento novo na estrutura econômica da região. Com base na abordagem sistêmica da inovação, o objetivo é identificar e caracterizar os investimentos relacionados ao setor aeronáutico efetuados na região e identificar as potencialidades do novo eixo geográfico de produção e manutenção de aeronaves para uma inserção setorial dinâmica, dada pela capacidade de integração ao sistema de inovação relacionado à indústria aeronáutica. Foram levantadas informações qualitativas de fontes primárias (aplicação de questionário) e secundárias. Para a análise, as informações foram organizadas segundo aspectos relevantes em atividades de inovação apontados no Manual de Oslo. Tecnologia e pessoal qualificado são fatores estratégicos na indústria em questão. A partir de tais requerimentos, constituem potencialidades presentes na RAC para uma possível inserção no sistema de inovação: (i) o ambiente institucional favorável no quesito sistema educacional, disponibilidade e treinamento de recursos humanos qualificados, que demonstrou capacidade de rápida estruturação para buscar atender a uma nova demanda que se materializou na região; (ii) existência de infra-estrutura de C\&T.

Palavras-chave: Sistema de Inovação, Indústria Aeronáutica, Região Administrativa Central.

* Administrador; mestre em Desenvolvimento Regional e Meio Ambiente - Uniara; professor das Faculdades integradas de Jaú - FIJ e Universidade Paulista - UNIP; consultor empresarial; e-mail: prof.fernandobueno@isbt.com.br.

** Doutora em Ciências Econômicas; professora colaboradora do Programa de Pós-Graduação em Desenvolvimento Regional e Meio Ambiente - Uniara; pesquisadora do Grupo de Estudos sobre Organização da Pesquisa e da Inovação (GEOPI)/Departamento de Política Científica e tecnológica (DPCT)

- Unicamp; e-mail: sonia.paulino@ige.unicamp.br. 


\section{Introdução}

O setor aeronáutico é considerado estratégico do ponto de vista do desenvolvimento tecnológico e da geração de empregos qualificados e figura como prioritário nas políticas públicas direcionadas ao desenvolvimento industrial e à inovação tecnológica. Trata-se de um setor condicionado pela internacionalização da produção e do desenvolvimento tecnológico. Ao mesmo tempo, a capacidade de inserção global e a competitividade estão em alguma medida ancoradas no desenvolvimento do sistema local de inovação constituindo tal intuito foco de políticas públicas em curso.

O artigo enfoca o estabelecimento, a partir de 2001, da indústria aeronáutica na Região Administrativa Central (RAC) do estado de São Paulo, o que introduziu um elemento novo na estrutura industrial da região, com repercussão na infra-estrutura de ensino e treinamento de recursos humanos. ARAC é composta por 26 municípios e tem como pólos econômicos Araraquara e São Carlos (SEADE, 2007).

Para a instalação da unidade industrial - para a realização de ensaios em vôo, montagem de aeronaves do segmento executivo, modernização e montagem de aviões militares - foi divulgada a realização de investimentos previstos de US \$150 milhões e criados em torno de dois mil empregos diretos (VALOR ECONÔMICO, 2008). Um segundo investimento, da ordem de $\mathrm{R} \$ 60$ milhões, foi realizado por outra empresa que começou a operar no mesmo ano na região e destinou-se à instalação de uma unidade de prestação de serviços de manutenção de aeronaves do segmento comercial. Foram criados 860 empregos diretos.

Com base na abordagem sistêmica da inovação, esse trabalho tem como objetivo identificar e caracterizar os investimentos relacionados ao setor aeronáutico ocorridos na RAC, assim como identificar as potencialidades que se delineiam para que esse novo eixo geográfico de produção e manutenção de aeronaves tenha inserção dinâmica, dada pela capacidade de integração no sistema de inovação voltado à indústria aeronáutica.

O período de observação é 2001 a 2008. Foram levantadas informações qualitativas oriundas de fontes primárias (aplicação de questionário) e secundárias (trabalhos acadêmicos, documentos e internet). Para a análise, as informações foram organizadas segundo aspectos relevantes em atividades de inovação apontados no Manual de Oslo.

Após essa introdução, no item dois, com base em revisão bibliográfica, é abordada a configuração de sistemas setoriais e dos sistemas de inovação locais tendo como referência a formação de cadeias de produção globalizadas em setores intensivos em tecnologia. $\mathrm{O}$ item três dá continuidade à análise considerando a indústria aeronáutica brasileira. O item quatro trata do estabelecimento da indústria na Região

REVISTA UNIARA, $n .^{0} 21 / 22,2008 / 2009$
Administrativa Central. Por fim, no item cinco, é apresentada a conclusão.

\section{Cadeias globais de valor e sistemas de inovação}

Andersen et al. (2000) abordam que as características do sistema de inovação estão embasadas em um sistema composto por um fluxo de relações de interdependência entre diversos agentes/atores. As organizações são diferenciadas em relação aos seus objetivos, o que reflete na divisão do trabalho e na geração e utilização do conhecimento. Tais formatos produtivos e tecnológicos interagem com os demais atores do sistema de forma funcional de modo a caracterizar uma total interdependência dessas partes que compõem um sistema de inovação, sendo que o formato de articulação dessas interações irá refletir nas relações externas de produção.

A abordagem sistêmica e interdisciplinar da inovação inclui a influência de fatores institucionais, sociais, políticos e econômicos. Tais interações entre os fatores em um ambiente complexo e a trajetória do processo caracterizam a abordagem de sistemas de inovação (SI). Estes são definidos, de maneira genérica, como uma "ampla rede de arrasto" para capturar processos de inovação, seus determinantes e algumas de suas conseqüências. Na realidade os SI se comportam e se instituem de formas correlatas às características de seus ambientes e dos fatores que condicionam. Portanto, devem ser vistos e abordados como estruturas analíticas variáveis e sujeitas a comportamentos específicos em suas várias dimensões. O sistema nacional de inovação é constituído por uma rede de instituições públicas e privadas, cujas atividades e interações produzem e difundem novas tecnologias (LUNDVALL, 1995).

Um dos aspectos fundamentais na aplicação da abordagem sistêmica da inovação é a escolha do nível de agregação do objeto ao estudo. A partir deste entendimento e da própria trajetória evolucionista dos sistemas de inovação condicionada pelos efeitos da globalização, pode se estabelecer diversos recortes da realidade ou dimensões de atuação dos sistemas de inovação. Edquist (1997) destacou, além da dimensão nacional, as dimensões regional, a setorial, a supranacional. Vemos que a fragmentação estratégica dos processos inovativos passou a alimentar ou condicionar o mercado globalizado delimitando as ações nas suas esferas ou dimensões levando as empresas ou setores a vantagens competitivas.

O sistema setorial de inovação (SSI) ocupa papel determinante no sistema nacional de inovação, embora possa extrapolar as fronteiras nacionais, ou no sistema localizado no interior das fronteiras nacionais, uma vez que empresas de setores distintos geram tecnologias e interagem entre si e com o sistema de forma distinta.

As principais vantagens do enfoque em sistemas setoriais de inovação são o melhor entendimento da estrutura, das fronteiras e transformações dos setores, dos agentes e suas interações e para o desenvolvimento de novas indicações de políticas 
públicas (MALERBA, 2003).

As organizações estão inseridas em determinados contextos setoriais específicos que atuam como condicionantes das atividades inovadoras. Tais setores apresentam dinâmicas tecnológicas próprias, padrões competitivos e condições de acesso tecnológico distintos, o que, em tese, caracteriza a dinâmica setorial e o papel da inovação dentro do contexto. Para que a inovação seja capaz de ancorar setores de alta densidade tecnológica faz-se necessário uma estrutura articulada em que determinadas condicionantes dos processos de inovação e difusão tecnológica sejam equacionadas a partir das necessidades técnicas do setor. $\mathrm{O}$ entendimento da dinâmica setorial, em um modelo competitivo, se dá a partir da análise dos processos produtivos, importantes na questão produtividade, dos tipos de produtos e sua qualidade e do padrão competitivo em que a empresa está inserida dentro do setor de atividade. Os diversos setores de atividades como o de commodities, bens duráveis, ou difusores de progresso técnico, em função da estrutura competitiva específica de cada setor, passaram a ter, em níveis distintos, uma relação produtiva globalizada, considerando a estrutura local, grau de demanda e necessidades empresariais que conferem as condições internas e externas para as atividades inovativas (TIGRE, 2006).

$\mathrm{O}$ autor aponta ainda que o ritmo de incorporação ou aquisição de novas tecnologias é cadenciado pelo dinamismo do setor, ou seja, investimentos em tecnologia são realizados em fases de expansão de mercado; estes investimentos em ampliação de capacidade produtiva abrem portas para a incorporação de novas tecnologias e aproveitamento do aprendizado local acumulado. No entanto, determinadas empresas ou plataformas industriais não conseguem tirar proveito dessas oportunidades de inovação por não estarem comprometidas com investimentos prévios, realizar opções tecnológicas e formas de operação que implicam em custos irrecuperáveis e também devido às fragilidades das políticas públicas que suportariam os ambientes tecnológicos. Torna-se importante enfatizar que setores de alta densidade tecnológica dependem da inovação como recurso competitivo.

O sistema setorial de inovação, em função do cenário internacionalizado da produção, normalmente está parcialmente fora do ambiente nacional, ou seja, o processo, principalmente em setores de alto desempenho tecnológico como o setor aeronáutico, é diferente de outros setores.

O conceito de cadeias globais de valor auxilia no entendimento da distribuição dos ganhos ao longo da referida cadeia, com destaque para a importância da detenção de recursos intangíveis ( $\mathrm{P} \& \mathrm{D}$, design, branding, marketing) que possuem altas barreiras à entrada e proporcionam alto retorno. As competências são o portfólio das organizações implicando num saber e agir no sentido de integrar e transferir os

REVISTA UNIARA, $n .^{0} 21 / 22,2008 / 2009$ recursos e habilidades intangíveis centrais para a competitividade. A cadeia de valor de produção consiste na melhor adequação das etapas de produção, desde a concepção do produto até a entrega final para o consumidor. Sob esta ótica, os agentes presentes em cada uma das etapas da cadeia produtiva contribuem para aumentar o valor agregado do produto. O produto que chega ao consumidor final é a soma dos efeitos agregados em cada uma das etapas da cadeia produtiva, resultado da ação dos agentes e da coordenação entre eles. A partir deste conceito, vemos que as condições a partir das quais o produto chega ao consumidor, depende tanto das atividades internas à organização quanto da sua coordenação com outros elos ou etapas da cadeia produtiva da qual faz parte. Vale ressaltar que esta dinâmica produtiva, em relação aos elos de uma cadeia, é muitas vezes desigual em função do formato da rede e do cenário econômico industrial na qual está inserida, revelando agentes que capturam maior valor do que outros ao longo dos elos produtivos (KAPLINSKY; MORRIS, 2000).

A divisão dos processos produtivos, segundo fases e lugares, se reflete na descentralização geográfica das cadeias produtivas. Empresas em países desenvolvidos estão submetidas a condições sistêmicas normalmente mais favoráveis do que empresas inseridas em países de industrialização tardia. Entretanto, o acúmulo de competências e capacitação pode permitir uma trajetória não determinista, possibilitando que firmas em países de industrialização tardia, em alguns setores, possam adquirir um padrão de competitividade elevado (BELL, 1984; 1989; KATZ, 1985; LALL, 1994; HOBDAY, 1995; KIM, 1997; FIGUEIREDO, 2003; COSTA, 2003 apud OLIVEIRA, 2005).

O processo de geração e difusão tecnológica, elemento motriz que sustenta as cadeias globais de alto desempenho tecnológico, não se configura como um fato ou processo generalizado e homogêneo para todas as nações.

As economias locais de países em desenvolvimento ao entrarem no comércio internacional acabam por aderir a um novo conceito de exigência e buscam realizar o upgrading, estratégia essencial na busca e manutenção de vantagens competitivas. Na realidade, a globalização e os novos mercados são condicionantes de estratégias inovativas.

Vários elementos são considerados nesta análise, tais como o poder de governança dos diferentes segmentos que constituem as cadeias de produção, a capacidade inovadora que pode ser adquirida pelos diversos agentes envolvidos, bem como as relações entre os agentes e os mecanismos de coordenação entre os diferentes elos de uma cadeia de produção (HUMPHREY, 2003).

Então, dois aspectos ligados às cadeias globais de valor são amplamente considerados: o de governança e o de upgrading (HUMPHREY; SCHMITZ, 2000).

Desenvolvimento do sistema de inovação... 
A governança tem como foco as relações de poder entre os elos de uma cadeia produtiva, sobretudo, com o mercado global. Algumas evidências mostram que um determinado segmento pode dominar uma cadeia, determinando suas características e sendo responsável pelas atividades de upgrading que são realizadas pelos vários segmentos que a constituem. A esse domínio, como visto, dá-se o nome de governança que pode ser do tipo producer-driven e buyer-driven.

A questão do upgrading está ligada à inovação, pois consiste em fazer produtos de formas mais eficientes, agregando valor através de processos mais sofisticados. Ainda, segundo os autores mencionados, o upgrading pode ser de três tipos: com foco no processo, consiste em reorganizar métodos de produção e melhorar a eficiência operacional; com foco no produto, consiste em gerar produtos com maior valor agregado, gerar utilidade ao produto; e funcional visando a incorporar e deter novas funções dentro da cadeia como design e marketing.

As cadeias globais de valor encontram nas atividades inovativas possibilidades competitivas que possam sustentar as dinâmicas produtivas que, por sua vez, são fortemente dependentes da inovação de produtos e processos para a competitividade do setor.

Vemos que para enfrentar a rigorosa competição motivada pelas exigências do mercado externo, da concorrência internacional e de adequação dos padrões produtivos, as empresas passam a integrar suas atividades globalmente, quebrando sua cadeia de valor em funções discretas e alocando-as conforme a necessidade de penetração em mercados em crescimento e da captura de vantagens locais específicas. Trata-se, aqui, do comportamento das grandes empresas e de uma integração internacional de suas estratégias de produção e comercialização, mas também de suas trajetórias tecnológicas e dos seus posicionamentos frente aos principais concorrentes.

A abordagem das cadeias globais de valor, ao mesmo tempo em que contribui para o entendimento do contexto global, que incide sobre a dinâmica da cadeia de produção setorial, indica a importância das bases locais a partir das quais atuam os agentes constituintes das cadeias globais.

Cassiolato e Lastres (1999) afirmam que o essencial das atividades de inovação continua sendo desenvolvido no país de origem das empresas, segundo estratégias definidas em tais espaços, e, quando se internacionalizam, objetivam, principalmente, realizar atividades de monitoração e adaptações ao mercado local. A partir da década de 1980, ganharam espaço análises sobre o papel relativo ao local para compreensão do processo inovativo nas empresas, regiões e países, bem como a discussão sobre o caráter local da inovação a partir de análises que privilegiam o papel do ambiente e da interação entre diferentes agentes como elemento de promoção da inovação.

REVISTA UNIARA, $n .^{0} 21 / 22,2008 / 2009$
Essa literatura ressalta que a interação entre tecnologia e contextos locais tem pape fundamental na geração de inovações, por meio de mecanismos específicos de aprendizado formados por um quadro institucional local específico. A partir daí, diferentes contextos locais com diferentes estruturas institucionais terão processos inovativos qualitativamente distintos. O motivo central de muitas das análises realizadas refere-se à tentativa de explicar as razões dos significativos níveis de concentração em nível mundial da taxa de introdução de inovações, com algumas regiões, setores e empresas tendendo a desempenhar o papel de principais indutores de inovações, enquanto outras parecem ser relegadas ao papel de adotantes.

Segundo Humphrey e Schmitz (2000), a inovação pode estar relacionada a padrões globais, originários do setor público e privado, que deveriam incentivar sistemas locais de produção adequando-se às novas especificações. A realização do upgrading em ambientes locais é um condicionante para a sustentação de organizações em cadeias globais. No entanto, a estrutura local ligada aos sistemas de inovação produz efeitos positivos ou negativos nesta sustentação e os setores são influenciados por esta dinâmica produtiva. As características dos diversos setores associadas às capacidades inovativas em âmbito local determinam as formas de relações de governança nos diversos elos de uma cadeia de valor afetando positivamente ou negativamente as possibilidades de desenvolvimento econômico local

No que se refere às ações para fomentar os ambientes locais, os agentes locais devem aproveitar o conhecimento adquirido para atender os mercados externos e diversificar seu conhecimento em outras direções, produzindo novos produtos e explorando novos mercados. É evidente que há um processo de aprendizado ao atender mercados externos, levando as organizações a novas posturas e dinâmicas produtivas e a atuação em novos mercados. Este cenário revela um mercado globalizado, em que as redes produtivas e de comercialização internacionais se constituem como ferramentas competitivas.

De acordo com Rózga (2002), a globalização pressiona o dinamismo econômico aguçando a competitividade global fazendo crer na necessidade em inovar para se continuar perpetuando no mercado. $O$ paradoxo se evidencia a partir deste formato, ou seja, os ambientes locais, mesmo em uma economia global são fundamentais para a competitividade industrial. As ações estratégicas no local condicionam as condições competitivas no sentido de utilizar recursos humanos, tecnológicos, políticos e econômicos provenientes de um território (ambiente) em prol de necessidades produtivas específicas. $\mathrm{O}$ ambiente local das empresas se refere aos insumos de trabalho, capital de risco e estes insumos se materializam nos trabalhadores das empresas, universidades e instituições de pesquisa locais. No caso das empresas,

Desenvolvimento do sistema de inovação... 
este insumoé frequentemente reconhecido como conhecimentos e habilidades tácitas, os serviços como engenharia, consultoria jurídica que se constituem nas próprias regiões, devido à importância dos contatos diretos com as pessoas.

Este autor afirma que em um ambiente local a inovação não depende apenas da empresa-âncora e sim de um conjunto de ações complementares condicionadas a uma coordenação e articulação dos esforços coletivos dos grupos de empresas pertencentes a uma cadeia de suprimentos, centros de pesquisas, universidades e políticas públicas adequadas aos objetivos coletivos. Esta dinâmica articulada não nasce do dia para noite; é um processo de longo prazo construído intrinsecamente a partir de bases estruturais sólidas.

Tigre (2006) aponta que as capacidades dinâmicas dos locais em relação ao fornecimento de subsídios para o desenvolvimento de processos inovativos estão postulados em dois fatores ou posturas relevantes para o desempenho inovativo que são:

- A importância das relações ou laços entre empresas e instituições no que tange aos processos de aprendizagem e acumulação de conhecimento em que se caracteriza a base para a fortificação e solidificação dos sistemas de inovação;

- A estrutura industrial local que subsidia as características inovativas internas das empresas e suas posturas quanto aos objetivos para um desenvolvimento tecnológico, bem como os estímulos regionais externos sobre a capacidade inovativa das empresas como a articulação eficiente dos aglomerados produtivos; a mão-de-obra qualificada; a base estrutural tecnológica formada por institutos de pesquisas, universidades e atores pertencentes à dinâmica tecnológica; a infraestrutura física e institucional como redes de transportes e logística, telecomunicações e capital de risco.

\section{A indústria aeronáutica brasileira}

O setor aeronáutico é marcado pela internacionalização da produção e da $\mathrm{P} \& \mathrm{D}$, orientando-se para o desenvolvimento de uma estratégia internacional a partir de uma base nacional, com coordenação centralizada. Esta tendência é comum às empresas, sobretudo as de alto conteúdo tecnológico, quando analisada sob a lógica orientada pelas cadeias globais de valor.

A partir do cenário, o modelo internacionalizado de produção é a condicionante em setores intensos em tecnologia, e a estrutura do ambiente local voltado ao desenvolvimento do produto e as articulações institucionais voltadas às políticas industriais são premissas que podem retratar a solidez produtiva e tecnológica de uma determinada região ou nação.

Bernardes e Pinho (2003), quando consideram a indústria de alta densidade

REVISTA UNIARA, $n .^{0} 21 / 22,2008 / 2009$ tecnológica, ressaltam as especificidades desses setores e a inserção em sistemas de inovação muito ativos e desenvolvidos. Há muitos formatos de arranjos que se moldam a partir das necessidades específicas de cada setor.

No setor aeronáutico, a internacionalização da produção segue esta mesma lógica global, pois atua em função de mercados específicos, com dinâmicas produtivas de alto conteúdo tecnológico e sob pressões globais de produção levando a um cenário internacionalizado.

Segundo Bernardes e Pinho (2003), as estratégias da indústria aeronáutica, no que tange a competitividade, estão baseadas fundamentalmente nas reduções de custos, produção customizada com maior flexibilidade, integração e rapidez na produção e entrega de aeronaves, além da globalização de fases do processo produtivo e especialização em atividades de desenvolvimento do produto. Aevolução dos mercados condicionou as empresas a um novo modelo competitivo. Trata-se da necessidade de mudanças estruturais produtivas e tecnológicas em função das novas exigências de mercado e da dinâmica aferida pelas exigências colocadas pela cadeia global de valor da produção que determina a trajetória do setor.

O mercado da aviação é repleto de riscos e incertezas, o público é extremamente seleto e restrito; os erros de cálculo, o não atendimento de uma simples exigência operacional de um cliente, ou mesmo os efeitos da concorrência podem acarretar um reflexo desastroso para as ambições da empresa. $\mathrm{O}$ elevado padrão de concorrência deste setor, focando de maneira agressiva a redução de custos de produção e de desenvolvimento de projetos, induziu as indústrias de aeronaves a se configurarem cada vez mais como indústrias de integração de sistemas. Este tipo de estratégia induz a uma série de conseqüências, das quais a mais explícita é a busca pela partilha de custos e riscos na elaboração de projetos. Desta forma, criam-se condições para uma espécie de padronização dos produtos e fornecedores. Passa a ser prática usual a observação de um fornecedor de sistemas comum às principais integradoras, como conseqüência direta, o número de fornecedores é reduzido de maneira significativa. Ao mesmo tempo, também é verificada uma tendência de especialização nos segmentos de atuação por parte das integradoras. Assim, na produção de aeronaves de grande porte (majors), a atuação fica centrada nas empresas Boeing e Airbus, enquanto que no segmento de aviões regionais (commuters), a produção fica concentrada principalmente nas empresas Bombardier e Embraer (OLIVEIRA, 2005).

As fusões e aquisições verificadas no setor retratam a tônica do mercado global de aviões de grande porte e médio/pequeno porte. O objetivo é reduzir o período de desenvolvimento dos produtos (aeronaves, sistemas de propulsão, aviônicos e estruturas) e os custos de produção a partir da padronização e enxugamento da 
cadeia produtiva com tecnologia e capacidade de partilha de riscos de P\&D e ajustando-se às exigências para as certificações internacionais, como elementos centrais à competitividade. É importante salientar que todas essas fusões e aquisições são reflexos da internacionalização da produção que acaba por pressionar as empresas do setor a uma nova adequação produtiva em função de um novo modelo de negócio (OLIVEIRA, 2005).

A evolução da indústria em nível global e as tendências condicionadas às novas trajetórias estratégicas e de participação de mercado levam as integradoras a desverticalizar seus processos produtivos, partilhando riscos de desenvolvimento e aumentando sua participação de mercado. A indústria aeronáutica está dividida em quatro grandes blocos principais de fabricantes compostos pelas integradoras Boeing, Airbus, Embraer e Bombardier e pelos fabricantes de sistemas (turbinas). Essas integradoras se dividem, por segmentos, da seguinte forma - Boeing/Airbus: Comerciais/grande porte (Boeing tem uma pequena participação no segmento de aviões regionais) e; Embraer/Bombardier: executivo e defesa - pequeno porte.

Analisando a articulação atual da cadeia produtiva, identifica-se um primeiro bloco composto pelas integradoras de sistemas; o segundo bloco é composto pelos parceiros de risco (sistemas complexos) internacionais; no terceiro bloco identificamos os fornecedores de subsistemas (complexos) também internacionais em que o grau de concentração também é forte, envolvendo uma qualificação tecnológica grande em estruturas, carenagens de turbinas, controles de vôo, trens de pouso, frenagem entre outros; o último grande bloco é formado por fornecedores de insumos semiacabados, peças fundidas, usinagem, prestação e serviços homem-hora ou máquinahora para manutenção e reparos em aeronaves e subsistemas menos complexos, além dos serviços de montagens de partes.

O setor aeronáutico, a partir deste contexto, evolui em suas articulações comerciais e produtivas. A própria evolução tecnológica e o padrão de consumo formam os elementos norteadores dessas mudanças. Para abordar as mudanças ocorridas a partir dos anos 90 na indústria aeronáutica brasileira, induzidas pelas novas condições vigentes no mercado global, Bernardes (2000) afirma que nesta etapa os padrões e modelos relacionados à concorrência modificaram-se de modo que os fatores críticos de competitividade tomaram outros rumos, ou seja, as fontes de vantagens competitivas da indústria aeronáutica passaram por uma reestruturação e fatores antes desprezados ganharam peso no contexto.

O grau de segmentação da indústria aeronáutica foi o elemento condicionante da mudança organizacional da cadeia produtiva, uma vez que a lógica deste mercado é fortemente segmentada. A lógica deste processo de reorganização obedece a especificidades, pois trata-se de bens produzidos em pequeno número, de alta

REVISTA UNIARA, $n .^{0} 21 / 22,2008 / 2009$ complexidade tecnológica levando a uma necessidade de aproveitamento das economias de especialização; as economias de escala são centrais nesta nova articulação global.

A partir de meados dos anos 1990, a estratégia de verticalização e de domínio das tecnologias críticas para a produção de aeronaves foi substituída pela de integração de sistemas (assembling) com tecnologia incorporada. A produção de aeronaves passou de um problema industrial tradicional (make ou buy) a um problema logístico. Daí decorreu a hierarquização da cadeia de produção em três categorias: no topo os parceiros de risco, que são sócios em projetos e usualmente são envolvidos desde as fases iniciais do projeto; em seguida estão os fornecedores que são firmas responsáveis pela entrega de outros sistemas funcionais; e na base da organização industrial estão as firmas subcontratadas, que prestam serviços em atividades de menor conteúdo tecnológico (GOMES et al., 2005).

Setores de alto desempenho tecnológico estão ligados a sistemas setoriais de inovação que usualmente extrapolam os limites da fronteira nacional e são condicionadas pela cadeia de produção globalizada, cuja localização geográfica deixa de ser um fator de extrema relevância para a condução dos negócios da organização. A indústria aeronáutica configura-se dentro deste modelo.

Dessa maneira, o modelo de negócios da empresa-âncora da indústria aeronáutica brasileira é baseado em outsourcing/assembly adequados ao desenvolvimento de produtos classificados como complexos (PINTO et al., 2007). O cenário produtivo mundial do setor aeronáutico é traçado a partir de uma série de determinantes e remete a evidências que comprovam a importância dessas cadeias de valor globalizadas, expressas no sistema setorial de inovação.

Lima et al. (2005) indicam que as perspectivas para um fortalecimento da cadeia produtiva aeronáutica nacional estão em função da distribuição internacional da indústria, da nova dinâmica organizacional calcada na redução dos custos de produção, na logística, além do nível de qualificação da mão-de-obra. Tal modelo de negócio reflete a dinâmica global do setor caracterizando-se como um fator de competitividade (ALEM; CAVALCANTI, 2005).

O setor aeronáutico no Brasil tem sua dinâmica e força concentradas no segmento commuters (pequeno porte). Os condicionantes para isto são vários, partindo do peso econômico que este segmento representa na pauta de exportações até a característica tecnológica de ponta, representada nesta indústria (OLIVEIRA, 2005).

Em função do alto valor agregado ao produto final, os commuters se diferenciam substancialmente da maioria dos outros produtos exportáveis, além de estarem inseridos num mercado de extrema concorrência em que há elevadas barreiras naturais à entrada e seus principais fornecedores/parceiros estão localizados além das 
fronteiras nacionais. Em alguns componentes críticos, o esforço tecnológicoé intenso, ao ponto de exigir uma base mundial de mercado para lhe dar sustentação.

Bernardes e Pinho (2003) consideram como elemento central para a indústria aeronáutica as especificidades das competências tecnológicas adquiridas para fabricação competitiva dos principais componentes aeronáuticos. A constituição de competências tão rigorosas requer a inserção num sistema de inovação muito ativo e desenvolvido e uma longa trajetória de aprendizado e acumulação de conhecimento.

Nesse caso, fatores relacionados a políticas públicas também se configuram como elementos fundamentais na sustentação de uma cadeia internacionalizada, pois subsidiam, sobretudo, o fortalecimento do sistema local.

Nadvi e Halder (2002) abordam que os setores de alto desempenho tecnológico são aqueles que, em função da própria natureza das atividades, atuam em cadeias globais de valor, porém, encontram nos ambientes produtivos locais fontes de vantagens competitivas fundamentais para a sustentação dessas cadeias globais. A questão são os desafios desses ambientes locais em estabelecer uma relação de parceria a partir de atividades complementares que necessitam de alto desempenho tecnológico.

As capacidades dinâmicas e as possibilidades dos ambientes locais de participarem de cadeias globais estão em função da estrutura articulada entre os vários agentes locais que participam da formação de aglomerados. Pensando em indústria de alto conteúdo tecnológico, em interface com um mercado extremamente específico, tornase fundamental o acesso a recursos financeiros através de órgãos de fomento, de mão-de-obra técnica para $\mathrm{P} \& \mathrm{D}$, de credibilidade e confiabilidade em relação à marca de seus produtos, capacidade gerencial e logística, para que possa se manter em uma posição de mercado assegurando a continuidade e a competitividade (ALEM; CAVALCANTI, 2005)

Vários trabalhos têm se dedicado à análise da indústria aeronáutica brasileira, (BERNARDES, 2000; BERNARDES; OLIVEIRA, 2002; BERNARDES; PINHO, 2003; OLIVEIRA, 2005; ALEM; CAVALCANTI, 2005; GOMES et al., 2005; LIMA et al., 2005; PINTO et al., 2007) buscando traçar o histórico da formação e evolução do pólo aeronáutico brasileiro de São José dos Campos, que tradicionalmente tem concentrado a cadeia produtiva e inovativa do setor em questão, bem como fornecer indicações sobre os desafios que se colocam para o sistema de inovação local.

De modo geral, verificou-se que a reorganização do arranjo produtivo aeronáutico ocorreu desarticuladamente e sem uma coordenação institucional integrada abrangendo as autoridades federais, estaduais e regionais, tendo resultado na fragilização do sistema de inovação local (BERNARDES; PINHO, 2003).

REVISTA UNIARA, $n .^{0} 21 / 22,2008 / 2009$
Ante esse cenário, o setor vem constituindo objeto de políticas públicas a partir da ação dos governos estadual e federal.

$\mathrm{Na}$ esfera federal, cabe mencionar a atuação do Banco Nacional de Desenvolvimento Econômico e Social (BNDES) voltada ao adensamento da cadeia produtiva da indústria aeronáutica. Tem-se como objetivo apoiar a empresa-âncora e fortalecer a cadeia produtiva local. Identifica-se a necessidade desenvolver, com o engajamento da empresa âncora, políticas de fomento ao incremento do conteúdo nacional em seus produtos, pelo aumento da capacitação industrial e tecnológica da indústria aeronáutica brasileira (PINTO et al., 2007).

Com vistas a fomentar o fortalecimento do sistema de inovação, o BNDES aprovou, em maio de 2008, recursos para Instituto de Pesquisas Tecnológicas (IPT) e Fundação de Amparo à Pesquisa do Estado de São Paulo (FAPESP) para estruturar um laboratório, e financiar projetos de pesquisa em estruturas leves, a ser instalado no Parque Tecnológico de São José dos Campos (Agência FAPESP, 09/06/2008).

Deve ser mencionada ainda a Política de Desenvolvimento Produtivo (PDP), apresentada em maio de 2008 e coordenada pelo Ministério do Desenvolvimento, Indústria e Comércio Exterior. APDP utilizará recursos do BNDES e definiu uma estratégia de liderança mundial com vistas a manter ou posicionar setores ou empresas brasileiras entre os principais players mundiais em suas atividades. A indústria aeronáutica foi enquadrada nessa categoria, juntamente com mineração e siderurgia e o complexo produtivo do bioetanol. O objetivo é construir e consolidar a competitividade em áreas de alta densidade tecnológica. Identificase como desafio a elevação da capacidade de inovação das empresas brasileiras, como condição para agregar valor aos produtos nacionais, ampliar a competitividade das empresas no mercado interno e fortalecer a inserção externa do país (INOVAÇÃO UNIEMP, 2008).

O governo estadual de São Paulo, por meio da Secretaria de Ciência, Tecnologia e Desenvolvimento Econômico (SCTDE), iniciou projetos para favorecer a inovação. O projeto "Estratégia para ciência, tecnologia e inovação em São Paulo: universidades, institutos de pesquisa e empresas" apresenta com uma conquista importante a criação do Parque Tecnológico de São José dos Campos, em 2006, com a participação da Embraer. O projeto, coordenado pela SCTDE e pela FAPESP, contou com recursos da Financiadora de Estudos e Projetos (Finep), ligada ao Ministério de Ciência e Tecnologia, por meio do edital de Projetos Estruturantes que visam a fortalecer o sistema de ciência, tecnologia e inovação (CT\&I) nos estados, bem como com contrapartida dos governos estadual e municipal. E apresentou como um dos resultados a criação do Parque Tecnológico de São José dos Campos, que abriga um centro de P\&D da Embraer (INOVAÇÃO UNIEMP, 2007).

Desenvolvimento do sistema de inovação... 
Verifica-se que a tônica das políticas voltadas ao fortalecimento do sistema de inovação localé dada pela busca da implementação integrada políticas industriale tecnológica.

\section{A indústria aeronáutica na Região Administrativa Central}

Em 2001, foi inaugurada na Região Administrativa Central (RAC) de São Paulo, no município de Gavião Peixoto, uma unidade da empresa-âncora da indústria aeronáutica brasileira destinada à realização de ensaios em vôo, montagem e reforma de aeronaves dos segmentos executivo e de defesa.

No mesmo, foi dado início às atividades do centro de manutenção de aeronaves do segmento comercial instalado em São Carlos pela empresa líder no mercado brasileiro de transporte aéreo. O centro de manutenção se dedica à realização da manutenção pesada em aviões Airbus e Fokker 100, utilizando mão-de-obra especializada. A empresa, em função do significativo crescimento de suas atividades e dos gargalos identificados na cidade de São Paulo (aeroportos de Congonhas e Guarulhos) no que tange à manutenção de aeronaves, desconcentrou suas atividades de prestação de serviços para o interior a partir de esforços próprios e com o apoio da prefeitura locale do governo do estado, por meio do Departamento Aeroviário do Estado de São Paulo (DAESP). A atividade de manutenção é considerada pelo setor como um serviço especializado de alto valor agregado.

A instalação de unidades destinadas à montagem e manutenção de aeronaves na RAC introduziu um elemento novo na estrutura econômica da região.

Destacam-se na economia da RAC a agropecuária e a indústria. Os municípios de Araraquara e São Carlos constituem os pólos econômicos da região e possuem estruturas industriais deferentes. A região tem posição geográfica considerada privilegiada permitindo utilização de sistema viário multimodal, com rodovias, ferrovias e grande número de vias secundárias (SEADE, 2007).

A escolha da localização da unidade para ensaios em vôo e montagem de aeronaves na RAC decorreu de estudos e análises que contemplaram, no seu início, 363 localidades em todo o país, levando em conta aspectos técnicos, industriais, logísticos, de infra-estrutura e custo, estratégicos e de segurança (DEFESANET, 2002).

A instalação da unidade da empresa-âncora na RAC teve incentivos do governo estadual por intermédio do Protocolo de Entendimento com o Governo do estado de São Paulo, assinado em 2000. A instalação da planta para sediar atividades de ensaios em vôo e atividades industriais das aeronaves dos mercados de defesa e de aviação corporativa da empresa contou com o aporte de recursos da empresa e com o apoio do governo estadual responsável pela infra-estrutura (terreno, obras de infra-estrutura interna - como arruamentos, redes de água, luz e esgoto), acesso viário e fornecimento de energia elétrica até a porta da fábrica.

A vocação e as atividades da unidade instalada na RAC deve ser entendida a partir da sua integração com as demais unidades da empresa-âncora, sobretudo a unidade sede, localizada em São José dos Campos. Assim, por exemplo, a fuselagem e as asas de jatos executivos montados na unidade são produzidas na unidade de Botucatu; outras peças vêm de outras fábricas instaladas no pólo de São José dos Campos (VALOR ECONÔMICO, 2008).

Hoje, a infra-estrutura física disponível na unidade instalada na RAC é composta de uma pista de testes, de instalações equipadas para montagem e manutenção de jatos executivos, produção de asas para dois modelos de jatos executivos, modernização e produção de aviões militares, pintura das aeronaves, fabricação de móveis para o interior das aeronaves. Também foi criado um sistema logístico para receber peças e equipamentos importados e de fornecedores locais (VALOR ECONÔMICO, 2008).

No quadro a seguir são apresentados aspectos relacionados com atividades de inovação identificados na RAC.

\begin{tabular}{|c|c|c|}
\hline & $\begin{array}{l}\text { Aspectos ligados ao } \\
\text { desenvolvimento de inovações }\end{array}$ & $\begin{array}{l}\text { Aspectos ligados ao desenvolvimento de } \\
\text { Inovações presentes na RAC }\end{array}$ \\
\hline \multirow{3}{*}{ 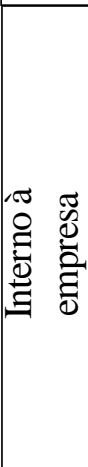 } & Objetivos & $\begin{array}{l}\text { Mercado - Consolidação da posição no } \\
\text { segmento de jatos executivos } \\
\text { Produto - Melhorias substanciais em } \\
\text { aeronave militar }\end{array}$ \\
\hline & Estágio alcançado & $\begin{array}{l}\text { Em progresso (jatos executivos) } \\
\text { Bem-sucedida (aeronave militar) }\end{array}$ \\
\hline & Infra-estrutura física & $\begin{array}{l}\text { Instalações para montagem de aeronaves } \\
\text { para ensaios } \\
\text { Instalações para modernização de aeronaves } \\
\text { militares } \\
\text { Pista de testes }\end{array}$ \\
\hline \multirow{2}{*}{ 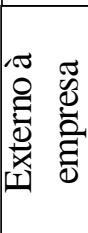 } & $\begin{array}{l}\text { Recursos humanos } \\
\text { Infra-estrutura de ensino } \\
\text { Infra-estrutura de treinamento }\end{array}$ & $\begin{array}{l}\text { Instituições de ensino técnico e superior } \\
\text { Instituições de suporte: treinamento }\end{array}$ \\
\hline & Infra-estrutura de C\&T & $\begin{array}{l}\text { Universidades e outras instituições de } \\
\text { ensino superior: grupos de pesquisa }\end{array}$ \\
\hline
\end{tabular}

Quadro. Indústria aeronáutica e atividades de inovação na Região Administrativa Central (SP). Fonte: Elaboração própria com base em OCDE/FINEP, 2005.

Desenvolvimento do sistema de inovação... 
a) Objetivo da inovação

Os objetivos da inovação podem relacionar-se a produtos, mercados, eficiência, qualidade, capacidade de aprendizado e de implementação de mudanças (OCDE/ FINEP, 2005).

A participação nos esforços de inovação da empresa decorre da vocação definida para a unidade industrial localizada na RAC (ensaios em vôo, montagem e manutenção de aeronaves dos segmentos executivo e de defesa) e reflete a estratégia empresarial voltada para a consolidação da participação no mercado global de jatos executivos, investindo na fabricação de modelos menores, mais econômicos e baratos, bem como para o atendimento de contratos para modernização e fornecimento de aeronaves firmados com o Comando da Aeronáutica. ${ }^{1}$

b) Estágio do processo de inovação

Com relação ao estágio alcançado nas atividades de inovação, no segmento de jatos executivos dois modelos de jatos encontram-se na fase de ensaios em vôo. E no segmento de defesa, o primeiro ALX Super Tucano foi entregue à Força Aérea Brasileira em 2003. No momento, encontra-se em andamento o projeto de modernização do caça F-5 BR.

c) Atividades de inovação

A inovação envolve várias atividades não incluídas na pesquisa e desenvolvimento (P\&D), tais como as fases finais de desenvolvimento para a pré-produção, a produção e a distribuição, as atividades de suporte como o treinamento. Nesse sentido, "Outras preparações para a inovação" englobam atividades internas relacionadas com o desenvolvimento e a implementação de inovações de produto e de processo não consideradas na $\mathrm{P} \& \mathrm{D}$ (como o desenho industrial, a engenharia e a colocação em funcionamento, e a produção para testes e ensaios visando a examinar o desempenho do produto novo ou com melhorias substanciais) (OCDE/FINEP, 2005).

A participação da unidade em atividades de inovação pode ser evidenciada pela infra-estrutura física disponível.

Cabe mencionar que o processo de inovação envolve a aquisição de bens e equipamentos requeridos para a implementação de produtos e processos novos ou melhorados. Trata-se da aquisição de bens de capital para inovação: terras e edificações, máquinas, instrumentos, equipamentos, softwares, computadores, bases de dados computacionais (OCDE/FINEP, 2005).

$\mathrm{Na}$ infra-estrutura física relacionada ao desenvolvimento de inovações foram identificadas instalações equipadas para algumas tarefas da modernização de

${ }^{1}$ A produção mundial de jatos executivos em 2007 foi considerada a maior de todos os tempos atingindo a cifra de 1138 unidades (VEJA, 11/06/2008).

REVISTA UNIARA, $n .^{\circ} 21 / 22,2008 / 2009$ aeronaves militares e para a montagem de aeronaves civis e militares destinadas a ensaios em vôo.

Destaca-se também a pista para testes, com cinco km de extensão, com estrutura para suporte a testes e ensaios em vôo que a qualifica como única no Hemisfério Sul e como a maior pista particular do mundo (VALOR ECONÔMICO, 2008).

d) Fornecedores

Com relação ao relacionamento com fornecedores, em 2003 a Kawasaki Heavy Industries inaugurou uma fábrica para produção de asas para jatos comerciais da empresa-âncora. Esta atividade foi assumida, em 2006, pela empresa- âncora em sua unidade instalada na RAC. O motivo apontado para a saída do fornecedor foi a inexistência de escala de produção que justificasse a instalação de fornecedores próximos à unidade da RAC (VALOR ECONÔMICO , 2008).

Esse padrão empresarial de desconcentração industrial não é diferente do ocorrido em outros setores de alto conteúdo tecnológico.

Sobre a natureza do processo de desconcentração industrial ocorrido na Região Metropolitana de São Paulo nas últimas décadas, aponta-se que a relocalização de unidades produtivas em outras regiões do estado não se deu com a desconcentração das chamadas funções corporativas superiores (marketing, desenvolvimento de produto, engenharia, $P \& D$ etc.) que permaneceram nas antigas sedes ou nas unidades de produção principal. Isso explica a elevada e mais que proporcional participação das ocupações tecnológicas no município de São Paulo e no seu entorno imediato (SUZIGAN, 2005 apud SEADE, 2006).

Na indústria aeronáutica, o custo de transporte tem pouca importância, pois se tratando de um produto final e de componentes intermediários de alto valor unitário, a redução de custos propiciada pela proximidade é insuficiente para ensejar por si mesma a aproximação de fornecedores aos fabricantes de aeronaves. Na realidade, as vantagens logísticas que a proximidade oferece em relação à organização da produção, acabam por ter um impacto menor na indústria aeronáutica que produz bens fabricados sob encomenda e em lotes pequenos. Esta é uma tendência provocada pelo alto grau de especificidade do setor (BERNARDES; PINHO, 2003).

e) Infra-estrutura de ensino e treinamento externo

A demanda por recursos humanos especializados foi acompanhada da criação na RAC de cursos específicos de nível técnico e superior.

Em 2001, foi assinado convênio com governo do estado, prefeitura de Araraquara, Serviço Nacional de Aprendizagem Industrial (SENAI) e Embraer, para a capacitação de mão-de-obra local para a indústria aeronáutica por meio da criação do curso de qualificação em produção aeronáutica. De 2001 a 2006 o curso foi desenvolvido em parceria com a Secretaria do Emprego e Relações 
do Trabalho (SERT), com recursos federais oriundos do Fundo de Amparo ao Trabalhador (FAT). Em 2007, por meio de um convênio com participação do Ministério do Trabalho, do SENAI, que participou do processo cedendo a infraestrutura física, e Prefeitura de Araraquara, no que tange ao fornecimento do transporte aos alunos, foi criado o Plano Setorial de Qualificação (Planseq) Aeronáutico que, no mesmo modelo do curso anterior, possibilitou a criação do curso de Trainee em produção aeronáutica. Todo o processo de articulação e montagem das grades curriculares do Planseq aeronáutico teve a participação do setor, sobretudo, da empresa-âncora. Foi um curso montado sob medida para a empresa.

Contou-se aqui com o envolvimento da prefeitura municipal na promoção de cursos de capacitação e requalificação profissional, a partir da identificação de demandas locais.

Ainda com relação à formação de recursos humanos em nível técnico para a indústria aeronáutica, a escola técnica estadual de Araraquara, gerido pelo Centro Paula Souza oferece, desde 2007, o curso técnico de manutenção aeronáutica com período de formação estabelecido para dois anos. As exigências para o ingresso no curso contemplam a maioridade e formação de nível médio. Trata-se de uma formação de nível técnico que tem enfoque em serviços de manutenções e reparos em aeronaves, viável na região em função de uma demanda produtiva explicitada.

Para suprir a demanda por mão-de-obra local qualificada em manutenção de aeronaves, foi formatado e implementado, em conjunto com o SENAI de São Carlos em 2006, um curso técnico de manutenção aeronáutica. Contou-se como aporte de recursos financeiros do Ministério do Trabalho por intermédio do Planseq aeronáutico.

No que diz respeito ao ensino de nível superior, em 2002 teve início o curso de engenharia aeronáutica oferecido pela Universidade de São Paulo (USP) em São Carlos, e que contou com apoio da Embraer na implementação com vistas à formação de recursos humanos com capacitação diferenciada (USP, 2007).

Uma parceira entre o Centro Federal de Educação Tecnológica de São Paulo (CEFET-SP) São Paulo e a Universidade Federal de São Carlos (UFSCar), viabilizou a formatação e implementação do curso Superior em Tecnologia em Manutenção de Aeronaves, o primeiro do país na área, que será oferecido em São Carlos com início previsto para o segundo semestre de 2008. Para a realização do curso houve a instalação de uma unidade do CEFET no campus de São Carlos da UFSCar. O objetivo foi aliar os conhecimentos da pesquisa da UFSCar com a aplicação prática desenvolvida pelo CEFET.

Há previsão do início das atividades de uma unidade do CEFET em Araraquara para o ano de 2009. Nos esforços para a atração de uma unidade CEFET para o município, a prefeitura municipal teve uma participação central. Elaborou um projeto para a instalação do CEFET, que foi apresentado e aprovado pelo governo federal. Prefeitos de 18 municípios da região firmaram parceria com a prefeitura de Araraquara para a construção do centro tecnológico. A intenção da prefeitura de Araraquara se baseia em dividir os custos, através de um consórcio entre os interessados na construção da unidade no que tange a terraplenagem, manutenção, segurança e outros quesitos de infra-estrutura local indispensável para que seja aprovada construção de uma das quatro unidades previstas a ter início em 2008 (TRIBUNA IMPRESSA, 23/05/07). A prefeitura local cederá a área e a infraestrutura necessárias para a viabilização da unidade. O governo federal será o responsável pela construção da edificação, instalações físicas e contratação de funcionários.

\section{f) Infra-estrutura de C\&T}

A infra-estrutura científica e tecnológica presente na RAC se apresenta como um elemento potencialmente importante para o desenvolvimento de inovações na indústria aeronaútica.

A RAC aparece com a segunda mais alta taxa de inovação do estado de São Paulo, após a macrometrópole formada pela capital e municípios próximos a ela (Sorocaba, Campinas e São José dos Campos). Como indicador de resultado do esforço tecnológico foi utilizada a produção científica considerada a partir dos dados indexados na base Science Citation Index Expanded (SCIE). Os municípios de São Carlos e Araraquara são destacados a partir da presença de universidades públicas e institutos de pesquisa (USP, UFSCar, Unesp e Embrapa). (FAPESP, 2005 apud SEADE, 2006).

Atendo-se às competências em aeronáutica instaladas nas universidades públicas presentes na RAC, podem ser mencionados os grupos de pesquisa ligados às áreas de conhecimento "engenharias" (Engenharias Mecânica, de Materiais e Aeronáutica) e ciências exatas (Ciência da Computação e Física) atuantes nas universidades localizadas em São Carlos. Neste município estão localizados ainda o Centro de Caracterização e Desenvolvimento de Materiais, administrado pela UFSCar e Unesp, e o Núcleo de Manufatura Avançada (Numa).

Verifica-se a presença de infra-estrutura de C\&T com potencial para constituir fonte de conhecimento para novas tecnologias para aeronaves em áreas sensíveis para a indústria, como o desenvolvimento de motores, de novos materiais e a otimização de projeto aerodinâmico.

Em suma, a nova característica da estrutura industrial da região, dada pela presença a partir de 2001 de atividades de produção e manutenção de aeronaves, foi 
acompanhada de ações de apoio dos governos tanto para a instalação das unidades de montagem de manutenção de aeronaves como para a criação de infra-estrutura de ensino e treinamento de recursos humanos.

Evidencia-se a presença de atores apontados como relevantes em sistemas de inovação: empresa inovadora, infra-estrutura de ensino e treinamento, infra-estrutura de C\&T, incentivos dos governos no níveis estadual e municipal.

\section{Conclusão}

A questão proposta para análise no artigo é consoante com as políticas públicas em curso voltadas à indústria aeronáutica, buscando contribuir para a identificação de oportunidades para o fortalecimento do sistema de inovação local, em um setor fortemente internacionalizado.

O estabelecimento da indústria aeronáutica na RAC é marcado pela instalação de uma unidade da empresa inovadora, sendo que a participação da referida unidade no desenvolvimento de inovações ocorre a partir de uma atuação integrada com outras unidades da empresa. Funções corporativas consideradas superiores seguem concentradas na unidade sede: concepção, projeto, construção de protótipo.

A unidade industrial na RAC ocupa área de 17 milhões de metros quadrados, sendo que apenas 90 mil são de área construída, havendo potencial para crescer e abrigar novos projetos da empresa relacionados à modernização de aviões militares e à produção de novos jatos executivos.

Cabe atentar que os ensaios em vôo constituem uma das áreas consideradas fundamentais da indústria aeronáutica, juntamente com as áreas de projeto de aeronaves, eletrônica, materiais, motores (LIMA et al., 2005).

A disponibilidade de terrenos de grande dimensão, as condições do espaço aéreo, o baixo custo relativo e a qualidade da mão-de-obra têm se constituído em vantagens de localização importantes (BERNARDES; PINHO 2003). As duas primeiras estão na base da infra-estrutura para testes e ensaios em vôo presente na RAC, que é diferenciada e de difícil reprodução em outro espaço estrategicamente localizado.

Com relação aos aspectos internos à empresa, a infra-estrutura física e a localização da unidade instalada na RAC permitiram atender aos requisitos operacionais e estratégicos do negócio e ganhar em agilidade no desenvolvimento de produtos.

Mas as atividades inovadoras dependem também da variedade e da estrutura da articulação e da interação, necessárias para a implementação de uma inovação, da firma inovadora com os outros atores do sistema de inovação, com destaque para as interações com a infra-estrutura de C\&T.

REVISTA UNIARA, $n .^{0} 21 / 22,2008 / 2009$
Tecnologia e pessoal qualificado são fatores estratégicos na indústria em questão. A partir de tais requerimentos, constituem potencialidades presentes na RAC para uma possível inserção no sistema de inovação: (i) o ambiente institucional favorável no quesito sistema educacional, disponibilidade e treinamento de recursos humanos qualificados, que demonstrou capacidade de rápida estruturação para buscar atender a uma nova demanda que se materializou na região; (ii) existência de infra-estrutura de C\&T.

O desafio que se coloca para o novo eixo concentrador de investimentos ligados ao setor aeronáutico consiste na identificação e na criação de condições para que possa constituir um núcleo com capacidade para robustecer o sistema de inovação localizado no país com foco na indústria aeronáutica, podendo, como tal, ser beneficiário de políticas públicas de desenvolvimento tecnológico e inovação. Isso passa pela conexão da infra-estrutura instalada na região a projetos e atividades voltados ao desenvolvimento tecnológico e à inovação direcionados à indústria aeronáutica.

\section{Referências bibliográficas:}

AGÊNCIA FAPESP. Futuro mais leve. Agência de notícias da Fundação de Amparo à Pesquisa do Estado de São Paulo, 09/06/2008.

ALEM, ANA CLAUDIA; CAVALCANTI, CARLOS EDUARDO. O BNDES e o apoio à Internacionalização das Empresas Brasileiras: Algumas reflexões. Rio de Janeiro: Revista do BNDES, 2005.

ANDERSEN. B. et al. Knowledge and innovation in the new service economy. Cheltenham: Edward Elgar, 2000.

BERNARDES, R. Embraer: Elos entre Estado e mercado. São Paulo: Hucitec, 2000.

BERNARDES, R.; OLIVEIRA, L.G. Cluster aeronáutico brasileiro e a formação de um eixo produtivo aeronáutico. In: Encontro Brasileiro de Estudos Regionais e Urbanos. São Paulo: ABER, 2002.

BERNARDES, R.; PINHO, M. Inovação e aprendizado nas micro, pequenas e médias empresas do arranjo aeronáutico de são José dos Campos.In: LASTRES et al. (Orgs.) Pequena empresa - cooperação e desenvolvimento local. Rio 
de Janeiro: Relume Dumará, 2003, p.101-119.

CASSIOLATO, J.E; LASTRES, H.M.M. Inovação, globalização e as novas políticas de Desenvolvimento industrial e tecnológico. In: CASSIOLATO, J.E.; LASTRES H.M.M. Globalização e inovação localizada: experiências de sistemas locais no Mercosul. Brasília:IBICT/MCT, 1999.

DEFESANET. Embraer inaugura primeira etapa da unidade de Gavião Peixoto. 12 de junho de 2002. Disponível em: <www.defesanet.web.terra.com.br >. Acesso em: 10 abr. 2008.

EDQUIST, C. Systems of innovation - technologies, institutions and organizations, London: Pinter, 1997.

GOMES, Sergio B. Varella; BARTELS, Walter; LIMA, Jorge Claudio C. Oliveira; PINTO, Marco aurélio C.; MIGON, Marcio N. O desafio do apoio ao capital nacional na cadeia de produção de aviões no brasil. Rio de Janeiro: Revista do BNDES, 2005.

HUMPHREY, J; SCHMITZ, H. A governança em cadeias globais de valor, 2000. Disponível em: <www.need.org.br/artigodomes/imprime.php?id=5>. Acesso em: 20 jul. 2007.

HUMPHREY, J. Opportunities for SMEs. In: Developing countries to upgrade in a global economy. Geneva: International labour office, 2003. (SEED Working Paper, n. 43).

KAPLINSKY, R.; MORRIS, M. A handbook for value chain research, Brighton, UK: Institute of Development Studies, 2000.

INOVAÇÃO UNIEMP. Governo Paulista Articula Diferentes Projetos para Favorecer Inovação. Inovação Uniemp.Campinas, v.3, n.1, jan./fev. 2007.

INOVAÇÃO UNIEMP. Política de Desenvolvimento Produtivo. Inovação Uniemp, Notícias, 19 maio 2008.

LIMA, Jorge Cláudio C. Oliveira; PINTO, Marco Aurélio C; MIGON, Marcio N.; MONTORO, Guilherme C. Franco; ALVES, Marcelo de F. A cadeia

REVISTA UNIARA, $n .^{\circ} 21 / 22,2008 / 2009$ eronáutica brasileira e o desafio da inovação. Rio de Janeiro: Revista do BNDES, 2005.

LUNDVALL, B. National systems of innovation - towards a theory of innovation and interactive learning, London: Pinter, 1995.

MALERBA, F. Sectoral systems and innovation and technology policy. Revista Brasileira de Inovação, v.2.n.2, p. 329- 375, jul./dez. 2003.

NADVI, K.; HALDER, G. Local clusters in global value chins. Exploring dynamic linkages between Germany and Pakistan, IDS Working Paper 152. Brighton: Institute of Development Studies, 2002.

OCDE/FINEP. Manual de Oslo. Versão editada em Português. Finep, Rio de Janeiro, 2005.

OLIVEIRA, Luiz G. A cadeia de produção aeronáutica no Brasil: Uma análise sobre os fornecedores da Embraer, 2005. Dissertação (Doutorado) UNICAMP, 2005.

PINTO, Marco Aurélio Cabral; MIGON, Márcio Nobre; MONTORO, G. C. F. "Convergência público-privada no adensamento da cadeia produtiva aeronáutica brasileira". Revista do BNDES, Rio de Janeiro, v.14, n.28, p.145-170, dez. 2007.

RÓZGA, R. Entre globalización tecnológica Y contexto nacional y regional de innovación, In CORONA, L; HERNANDEZ, R. Innovación, Universidad e Indústria en el desarrollo regional, Plaza Y Valdéz, p.29-50, 2002.

SEADE. Atlas Seade da Economia Paulista, Fundação Sistema Estadual de Análise de Dados (SEADE), 2006. Disponível em: <www.seade.gov.br/produtos/ atlas/>. Acesso em: 02 jun. 2008.

SEADE. Região Administrativa Central. Foco, publicação integrante do diagnóstico para ações regionais da Secretaria do Emprego e Relações do Trabalho do Estado de São Paulo, Fundação Sistema Estadual de Análise de Dados (SEADE), 2007. n.10.

TIGRE, Paulo B. Gestão da Inovação: a economia da tecnologia no Brasil. Rio 106

Desenvolvimento do sistema de inovação.. 
TRIBUNA IMPRESSA. Jornal Tribuna Impressa, Araraquara, 23/05/2007.

UNIVERSIDADE DE SÃO PAULO. Formatura de engenheiros aeronáuticos confirma presença da USP no setor. Universidade Foco, USP, 06/02/2007.

Disponível em: <www.noticias.usp.br>. Acesso em: 18 abr. 2008.

VALOR ECONÔMICO. Phenom domina ares de Gavião Peixoto. Valor Econômico, São Paulo, 16/01/2008. Disponívelem:<www.fiesp.org.br>Acesso em: 10 abr. 2008.

Title:

DEVELOPMENT OF THE SYSTEM OF INNOVATION: THE ESTABLISHMENT OF THE AIRCRAFT INDUSTRY IN THE CENTRAL ADMINISTRATIVE REGION (SP).

\section{Abstract:}

The article intends to show the establishment of the aircraft industry in the Central Administrative Region (SP), in the last seven years, which introduced a new element in the economical structure of the region. Based on the innovation systemic approach, the objective is to identify and characterize the investments related to the aircraft industry segment carried out in the region and to identify the potentialities of the new production geographical axle and aircraft's maintenance for a dynamic setorial insertion, given by the capacity of integration to innovation system related to the aircraft industry. Some qualitative information was obtained from primary (questionnaires) and secondary sources. For the analysis, all the information was organized taking into consideration the most important aspects of the innovation activities according to the Oslo Manual. Technology and efficient staff are the strategic factors to this type of industry. Based on these requirements, they have potentialities in the Central Administrative Region (CAR) for a possible insertion in the innovation system: (i) the favorable institutional environment concerning the education system, availability and training of human qualified resources, which demonstrated fast structuring capacity seeking to attend a new demand that appeared in the region; (ii) Technology \& Science infrastructure.

Keywords: Innovation Systems, Aircraft Industry, Central Administrative Region. 